\title{
A genetic linkage map for the South African Angora goat
}

\author{
C. Visser ${ }^{\text {a,* }}$, R.P.M.A. Crooijmans ${ }^{\text {b }}$, E. Van Marle Köster ${ }^{\mathrm{a}}$ \\ a Department of Animal E Wildlife Sciences, University of Pretoria, Lynwood Road, Pretoria 0002, South Africa \\ ${ }^{\mathrm{b}}$ Animal Breeding and Genomics Centre, Wageningen University, Wageningen, The Netherlands
}

\section{A R T I C L E I N F O}

\section{Article history:}

Received 25 March 2010

Received in revised form 31 May 2010

Accepted 31 May 2010

Available online $\mathrm{xxx}$

\section{Keywords:}

Linkage map

Angora goats

Microsatellite markers

\begin{abstract}
A B S T R A C T
Despite their economical importance, relatively few molecular studies have been made on goats compared to other livestock species. The most recent goat map was published in 1998, and lacks complete genome coverage. A large number of discrepancies and especially inter-chromosomal re-assignments were reported between the 1998 goat linkage map and the sheep map. In this study 94 microsatellite markers were amplified in 12 half-sib South African Angora goat families for compilation of a genetic map, aiming to confirm or reject previously reported rearrangements and to improve the alignment between the ovine and caprine maps. The number of informative meiosis per marker ranged from 69 to 836, with an average of 518 . The microsatellites were mapped to 23 chromosomes, spanning $1352 \mathrm{cM}$ and resulting in an average marker interval of $23.0 \mathrm{cM}$. Marker orders were compared to the previously published goat maps, as well as to the ovine map. Six chromosomes (CHI 2 , $4,5,11,13$ and 19) showed rearrangements in marker order compared to the 1998 Schibler et al. goat map, while nine previously unmapped markers were conclusively assigned to eight chromosomes. Four of the previously reported intra-chromosomal rearrangements between the goat and sheep maps were confirmed to be either population specific or mapping errors. The verification of rearrangements in loci order will lead to improved alignment between the two maps, as well as improved efficiency of genome and fine mapping efforts in goats.
\end{abstract}

(C) 2010 Published by Elsevier B.V.

\section{Introduction}

Sheep and goats were the first domestic animals to be used for food production and contribute significantly to the agricultural sectors of small stock producing countries, including South Africa (Notter et al., 2007). The world goat population has grown by 66\% from 1985 to 2005 , while the sheep population decreased and the cattle population showed only a 9\% growth (Dubeuf and Boyazoglu, 2009). Both goat milk and goat meat production has increased significantly during this period. The growth in the goat population was mostly due to an increase in the goat numbers in the developing countries in Asia and Africa.

\footnotetext{
* Corresponding author. Tel.: +27 12420 3268; fax: +27 124203290 E-mail address: carina.visser@up.ac.za (C. Visser).
}

The Angora goat is the major contributor to goat production in South Africa. Since the early nineteen nineties South Africa is the major producer of quality mohair in the world, with a market share of $55 \%$ of the world market (Loots, 2007). Therefore, the Angora goat farmers in South Africa play a crucial role in enhancing the constant availability of quality natural fibers worldwide. The natural animal fiber market, including mohair, is also facing competition from synthetic fibers. As mohair is a specialist fiber with a niche market, producers will always face challenges to remain productive and competitive. Therefore, the South African producers have to adapt to demands for finer fiber, decreasing profit margins, a challenging production environment and changed land-use patterns.

Despite the important contribution of goats, the molecular tools developed for goats during the past decade are relatively limited compared to cattle and sheep (Maddox, 
Table 1

Family structure of herds included in the study.

\begin{tabular}{|c|c|c|c|c|}
\hline & Offspring year 1 & Offspring year 2 & Offspring year 3 & Total \\
\hline \multicolumn{5}{|l|}{ Herd 1} \\
\hline Sire 1 & 27 & 40 & & 67 \\
\hline Sire 2 & & 37 & 7 & 44 \\
\hline \multicolumn{5}{|l|}{ Herd 2} \\
\hline Sire 1 & 41 & 33 & 36 & 110 \\
\hline Sire 2 & 18 & 38 & 59 & 115 \\
\hline Sire 3 & 34 & 42 & 8 & 84 \\
\hline Sire 4 & 31 & 46 & 27 & 104 \\
\hline \multicolumn{5}{|l|}{ Herd 3} \\
\hline Sire 1 & 9 & 99 & 32 & 140 \\
\hline Sire 2 & & & 84 & 84 \\
\hline \multicolumn{5}{|l|}{ Herd 4} \\
\hline Sire 1 & & 41 & 23 & 64 \\
\hline Sire 2 & & 41 & 76 & 117 \\
\hline Sire 3 & 38 & 54 & & 92 \\
\hline Sire 4 & 54 & 37 & & 91 \\
\hline
\end{tabular}

2005). Physical and genetic linkage maps have been developed for most species, and together with other physical resources like libraries (BAC and cDNA), GenBank sequences, microarrays and proteomics have found direct application in direct selection on genetic differences underlying phenotypic variation (Sonstegard et al., 2001; Vignal et al., 2002; Baumung et al., 2004). Moreover, the bovine genome has been sequenced and hundreds of thousands of single nucleotide polymorphisms (SNPs) have been detected (Allan and Smith, 2008). Although the ovine genome sequence is lagging behind thousands of SNPs have also been identified (Maddox and Cockett, 2007). The bovine whole-genome radiation hybrid and linkage maps are created and updated at regular intervals (Prasad et al., 2007; Faraut et al., 2009), however the most recent version of the goat linkage map was published in 1998 and lacks complete genome coverage (Maddox and Cockett, 2007).

Genetic linkage maps are essential for identifying specific loci for quantitative traits. The current caprine maps available are however limited to the first low-resolution genetic map for the male goat genome constructed by Vaiman et al. (1996), followed by an improved male goat map by Schibler et al. (1998). The mapping of traits of economic importance in goats has mainly focussed on milk proteins (Moioli et al., 2007; Cosenza et al., 2008), the polled intersex syndrome mapped on chromosome 1 (Vaiman et al., 1997) and growth hormones (Gupta et al., 2009). This resulted in specific regions (i.e. the areas flanking the PISRT1 locus) with microsatellite marker saturation, while other regions were neglected. Although several QTL studies have been performed on small-stock species and partial linkage maps were created as by-products of these studies, these maps are mostly not publicly available (Maddox and Cockett, 2007).

At this stage the most common type of marker used in goat linkage map studies is microsatellite markers. The present goat map contains 307 loci, mainly microsatellite markers, with the majority of bovine origin. Although microsatellite markers are still useful, SNP markers, if available, are the best choice in molecular studies, mainly due to their high abundance and increased automation coupled with low cost (Toro et al., 2009). No mapped SNP markers have been reported for goats (Maddox and Cockett, 2007) and only $1.2 \%$ of bovine SNPs were proved to be polymorphic in goats (Maddox and Cockett, 2007), and is thus at present of little use in goat studies. SNP discovery projects for caprine SNPs are required and are currently underway.

There are a relatively large number of discrepancies between the goat map and both the sheep and cattle maps (Maddox, 2005), including many rearrangements of locus orders between the different maps. It is not certain which of these discrepancies are mapping mistakes, and which might be genuine inversions between species. The use of small populations and small numbers of microsatellite markers in conjunction with less error checking for the goat map, has lead to a less robust map with a need for further genetic map development.

This study reports a sex averaged genetic linkage map of the South African Angora goat containing 94 microsatellite markers. The markers were mapped on a large threegeneration half-sib population and will be used to perform a QTL study.

\section{Materials and methods}

\subsection{Family structure}

The genetic linkage map was constructed by genotyping three generations of Angora goat half-sib offspring, belonging to 12 different families. The families ranged from 44 to 140 offspring, with an average of 88 half-sib offspring per sire, as described in Table 1 . All the herds were kept outdoors and farmed under extensive systems. Farmers made use of group mating during the breeding season, while some practice over-mating at the end of the mating season. Whole blood samples $(5 \mathrm{ml})$ were collected at the stud farms, refrigerated and transported to the University of Pretoria. DNA was extracted from $100 \mu \mathrm{l}$ whole blood using respectively the Qiagen DNEasy Tissue kit at the University of Pretoria and the Invisorb blood mini HTS kit (Invitek) for the XtractorGene (Corbett Robotics) at Wageningen University according to the protocols of the respective manufacturers. Both blood and DNA samples are stored at the Grootfontein Agricultural Development Institute's BioBank, South Africa.

\subsection{Microsatellite markers and genotyping}

One hundred thirty four microsatellite markers were selected from the existing goat map database (http://locus.jouy.inra.fr/cgi- 
G Model

Table 2

Description of microsatellite markers used in linkage groups.

\begin{tabular}{|c|c|c|c|c|c|}
\hline Microsatellite & Chromosome assignment & No. of alleles & PIC & No. of informative meiosis & $\mathrm{TA}$ \\
\hline BM1312 & 1 & 11 & 0.648 & 374 & 56 \\
\hline ВМ3205 & 1 & 9 & 0.513 & 266 & 55 \\
\hline CSSM19 & 1 & 5 & 0.267 & 270 & 54 \\
\hline CSSM32 & 1 & 6 & 0.142 & 88 & 54 \\
\hline MAF64 & 1 & 7 & 0.716 & 676 & 58 \\
\hline INRA011 & 1 & 27 & 0.711 & 824 & 55 \\
\hline BMS2782 & 2 & 12 & 0.674 & 543 & 54 \\
\hline OarFCB11 & 2 & 5 & 0.322 & 184 & 56 \\
\hline INRA040 & 2 & 8 & 0.525 & 260 & 55 \\
\hline SRCRSP24 & 2 & 9 & 0.673 & 690 & 58 \\
\hline CSSM54 & 3 & 13 & 0.513 & 460 & 54 \\
\hline MCM58 & 3 & 20 & 0.698 & 696 & 54 \\
\hline INRA003 & 3 & 3 & 0.392 & 207 & 56 \\
\hline INRA006 & 3 & 11 & 0.703 & 820 & 55 \\
\hline OarHH64 & 4 & 6 & 0.633 & 385 & 56 \\
\hline OarCP26 & 4 & 8 & 0.485 & 519 & 56 \\
\hline MAF050 & 4 & 9 & 0.687 & 739 & 60 \\
\hline OarHН35 & 4 & 10 & 0.723 & 493 & 50 \\
\hline BMS1788 & 4 & 12 & 0.655 & 673 & 55 \\
\hline MAF70 & 4 & 8 & 0.645 & 721 & 58 \\
\hline OARFCB005 & 5 & 9 & 0.41 & 263 & 56 \\
\hline LSCV25 & 5 & 11 & 0.726 & 637 & 56 \\
\hline BMS1248 & 5 & 9 & 0.241 & 180 & 54 \\
\hline BM2830 & 5 & 9 & 0.517 & 539 & 56 \\
\hline BMC1009 & 5 & 9 & 0.593 & 361 & 54 \\
\hline ILSTS034 & 5 & 7 & 0.542 & 548 & 55 \\
\hline ВM0321 & 5 & 12 & 0.485 & 491 & 58 \\
\hline BM143 & 6 & 6 & 0.64 & 685 & 56 \\
\hline BM415 & 6 & 10 & 0.769 & 735 & 50 \\
\hline BM1329 & 6 & 7 & 0.713 & 450 & 54 \\
\hline BM4621 & 6 & 6 & 0.449 & 464 & 56 \\
\hline ILSTS087 & 6 & 9 & 0.484 & 518 & 58 \\
\hline SRCRSP08 & 6 & 8 & 0.578 & 547 & 58 \\
\hline INRABERN192 & 7 & 7 & 0.606 & 540 & 56 \\
\hline OarAE129 & 7 & 4 & 0.509 & 370 & 54 \\
\hline MCM527 & 7 & 5 & 0.571 & 565 & 56 \\
\hline CSSM47 & 8 & 7 & 0.306 & 221 & 56 \\
\hline MCM64 & 8 & 9 & 0.526 & 411 & 58 \\
\hline SRCRSP10 & 8 & 11 & 0.678 & 836 & 55 \\
\hline BM4208 & 9 & 12 & 0.776 & a & 54 \\
\hline INRA177 & 11 & 9 & 0.398 & 308 & 56 \\
\hline OarCP34 & 11 & 10 & 0.668 & 682 & 56 \\
\hline ILSTS045 & 11 & 5 & 0.549 & 524 & 55 \\
\hline BMS0712 & 12 & 9 & 0.689 & 675 & 56 \\
\hline INRA005 & 12 & 4 & 0.358 & 302 & 54 \\
\hline BMS2252 & 12 & 7 & 0.561 & 573 & 55 \\
\hline SRCRSP09 & 12 & 11 & 0.613 & 443 & 58 \\
\hline ILSTS033 & 12 & 10 & 0.562 & 575 & 55 \\
\hline IL2RA & 13 & 9 & 0.543 & 504 & 50 \\
\hline BMC1222 & 13 & 6 & 0.585 & 529 & 56 \\
\hline ILSTS059 & 13 & 4 & 0.445 & 468 & 55 \\
\hline BM4630 & 14 & 2 & 0.312 & 326 & 54 \\
\hline ILSTS011 & 14 & 7 & 0.625 & 684 & 58 \\
\hline ВМ0719 & 16 & 7 & 0.682 & 705 & 56 \\
\hline ВМ0121 & 16 & 9 & 0.609 & 522 & 56 \\
\hline HUJ614 & 16 & 7 & 0.413 & 451 & 55 \\
\hline OarVH098 & 17 & 6 & 0.647 & 610 & 56 \\
\hline OarFCB48 & 17 & 8 & 0.69 & 658 & 60 \\
\hline ILSTS058 & 17 & 12 & 0.722 & 682 & 56 \\
\hline BM8125 & 17 & 8 & 0.555 & 515 & 55 \\
\hline INRA210 & 18 & 9 & 0.403 & 264 & 54 \\
\hline INRA063 & 18 & 5 & 0.61 & 776 & 55 \\
\hline MCM104 & 18 & 7 & 0.603 & 774 & 55 \\
\hline MCM210 & 19 & 6 & 0.478 & 305 & 54 \\
\hline BMS0745 & 19 & 12 & 0.692 & 608 & 55 \\
\hline LSCV36 & 19 & 8 & 0.564 & 478 & 55 \\
\hline OARFCB193 & 19 & 6 & 0.641 & 610 & 55 \\
\hline MAF214 & 20 & 17 & 0.618 & 406 & 54 \\
\hline
\end{tabular}


Table 2 (Continued)

\begin{tabular}{|c|c|c|c|c|c|}
\hline Microsatellite & Chromosome assignment & No. of alleles & PIC & No. of informative meiosis & TA \\
\hline TGLA304 & 20 & 8 & 0.533 & 506 & 56 \\
\hline BM1225 & 20 & 6 & 0.513 & 398 & 55 \\
\hline ВM3517 & 20 & 15 & 0.671 & 441 & 55 \\
\hline SRCRSP05 & 21 & 9 & 0.714 & $\mathrm{a}$ & 58 \\
\hline BM7160 & 22 & 7 & 0.597 & a & 55 \\
\hline OarCP73 & 23 & 17 & 0.775 & 583 & 56 \\
\hline OLA-DRB & 23 & 15 & 0.721 & 575 & 60 \\
\hline BM1818 & 23 & 9 & 0.683 & 674 & 55 \\
\hline DRBP1 & 23 & 7 & 0.648 & 69 & 55 \\
\hline BM1258 & 23 & 10 & 0.643 & 640 & 55 \\
\hline MCM136 & 24 & 3 & 0.348 & 450 & 55 \\
\hline BMS1332 & 24 & 6 & 0.524 & 399 & 55 \\
\hline BMS2526 & 24 & 7 & 0.688 & 775 & 55 \\
\hline BР28 & 25 & 10 & 0.625 & 581 & 50 \\
\hline INRA206 & 25 & 9 & 0.747 & 572 & 56 \\
\hline TGLA040 & 25 & 7 & 0.472 & 464 & 56 \\
\hline HEL11 & 26 & 14 & 0.687 & 518 & 56 \\
\hline INRABERN172 & 26 & 8 & 0.657 & 823 & 55 \\
\hline LSCV52 & 26 & 7 & 0.648 & 821 & 55 \\
\hline LSCV46 & 26 & 3 & 0.205 & 199 & 55 \\
\hline BM6526 & 27 & 16 & 0.686 & 455 & 56 \\
\hline CSSM43 & 27 & 8 & 0.5 & 442 & 56 \\
\hline TGLA179 & 27 & 9 & 0.757 & 828 & 55 \\
\hline BMS1714 & 28 & 5 & 0.679 & 576 & 55 \\
\hline ILSTS087 & 28 & 9 & 0.484 & 518 & 58 \\
\hline BMC8012 & 29 & 3 & 0.368 & $\mathrm{a}$ & 55 \\
\hline
\end{tabular}

a Singletons.

bin/lgbc/mapping/common/intro2.pl?BASE=goat) and previously published literature to obtain sufficient genome coverage. Of these markers, nine were unassigned by Schibler et al. (1998). For some chromosomes certain markers were included, even if they were the only marker on the chromosome, as this linkage map study was the first phase of a QTL project. Coverage of at least three markers per chromosome was aimed for, but this was not always feasible due poor amplification, informativeness of some markers, as well as financial constraints. Markers were first screened for polymorphicity and amplification success in the 19 potential Angora sires. Finally, the 12 sires (with offspring) that expressed the highest levels of heterozygosity across all loci tested were selected for inclusion in the study. PCR was performed in a i-cycler (Bio-rad) and T1 Thermocycler (Biometra) using $30 \mathrm{ng}$ DNA, $2.94 \mu \mathrm{l}$ of the ABgene ${ }^{\circledR}$ PCR Master Mix (ABGene, $U K$ ) and $0.03 \mu$ l each of $40 \mathrm{pmol} / \mu \mathrm{l}$ reverse and forward primer. The PCR amplification was conducted in a $6 \mu \mathrm{l}$ final volume in 384-well PCR plates at the following conditions: $95^{\circ} \mathrm{C}$ for $5 \mathrm{~min}$, followed by 35 cycles of $96^{\circ} \mathrm{C}$ for $30 \mathrm{~s}, 45 \mathrm{~s}$ at annealing temperature and $90 \mathrm{~s}$ at $72{ }^{\circ} \mathrm{C}$ with a final extension step of $10 \mathrm{~min}$ at $72^{\circ} \mathrm{C}$.

\subsection{Linkage analysis}

Due to misidentification and recording errors that occur during mating under extensive production systems, the data was analysed using Cervus 3.0 (Marshall et al., 1998) and all aberrant individuals were removed from the study. Linkage analysis was performed with CRI-MAP 2.4 (Green et al., 1989) compiled for Windows XP. A LOD threshold of 6 was chosen to detect significant linkage, and lowered in increments (up to 1) until all markers could be assigned. Linkage groups were further analysed using the "build" option. Markers that could not be placed accurately with this option, were then included in alternative "fixed" orders. The final order (which resulted in the shortest map length) was verified with the "flipsn" option.

\section{Results}

From the 134 microsatellites initially selected, 94 markers were used in genotyping the whole population. The panel of 94 microsatellites included have a bovine (65), ovine (24) and caprine (5) origin. Of these, 90 markers were mapped to 23 chromosomes covering $1352 \mathrm{cM}$ over and resulting in an average marker interval of $23.0 \mathrm{cM}$. The remaining four markers were singletons and mapped to chromosomes $\mathrm{CHI}$, CHI21, CHI22 and CHI29. No markers could be selected or were associated with CHI10 and CHI15. Four markers (LSCV46, HEL11, TGLA040 and INRABERN172) were mapped to $\mathrm{CHI} 26$ and two markers to CHI28 (BMS1714 and ILSTS087) but due to poor informativeness, no orders could be estimated.

The number of alleles, PIC and number of informative meiosis for each marker is indicated in Table 2 . The average number of alleles per marker was 8.6 , whereas only 8 markers had less than 5 alleles. The average PIC value across all loci was 0.57. Twelve markers had a PIC value below 0.4. The average number of informative meiosis per marker was 518, ranging between 69 (DRBP1) and 836 (SRCRSP10).

Linkage groups were created using the two-point option with a LOD threshold of 6 . A total of 75 markers showed significant linkage (LOD $>6$ ) to at least one other marker. Seven more markers could be linked when the LOD threshold was decreased to 3 . The remaining markers formed part of the linkage groups with a $\operatorname{LOD}>1$, and were verified to belong to the same linkage groups as previously reported by Schibler et al. (1998). The linkage groups covered 23 autosomes spanning $1326 \mathrm{cM}$, and ranged in size from $26 \mathrm{cM}$ to $129 \mathrm{cM}$. Linkage groups generally exceeded $40 \mathrm{cM}$, except on chromosomes CHI7 (27 cM), CHI8 (26 cM), CHI13 (31 cM), CHI18 (26 cM), CHI25 (26 cM) and CHI27 $(30 \mathrm{cM})$. The intervals between consecutive markers within linkage groups ranged between 2 and $51 \mathrm{cM}$. The final linkage map generated in this study is presented in Fig. 1

Several chromosomes showed marker order differences when compared to the previously published map by 

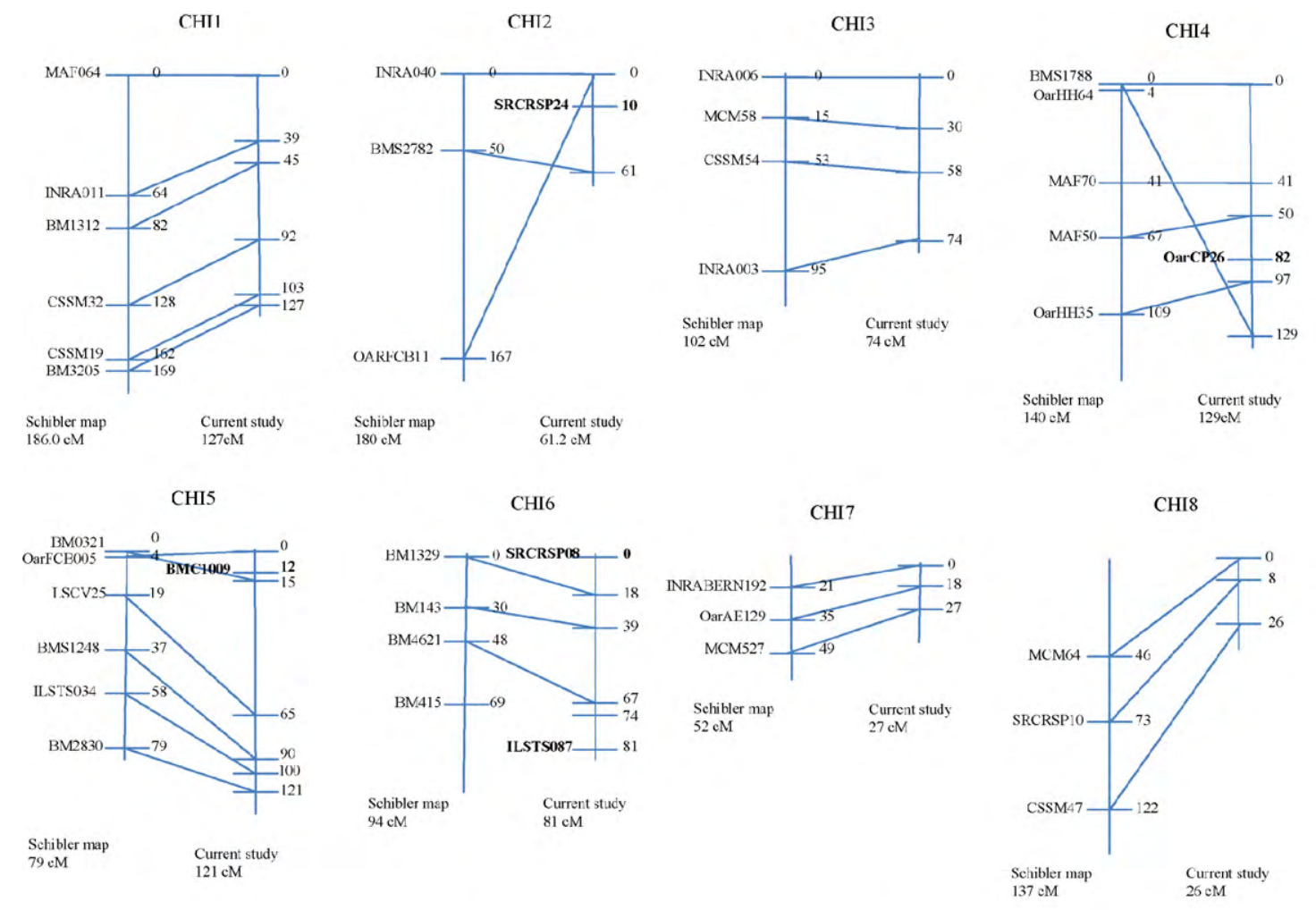

CHI11

\section{$\mathrm{CH} 12$}

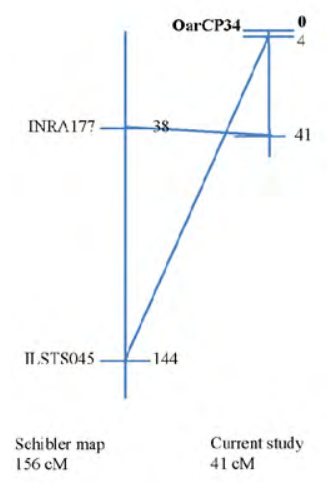

CHI13
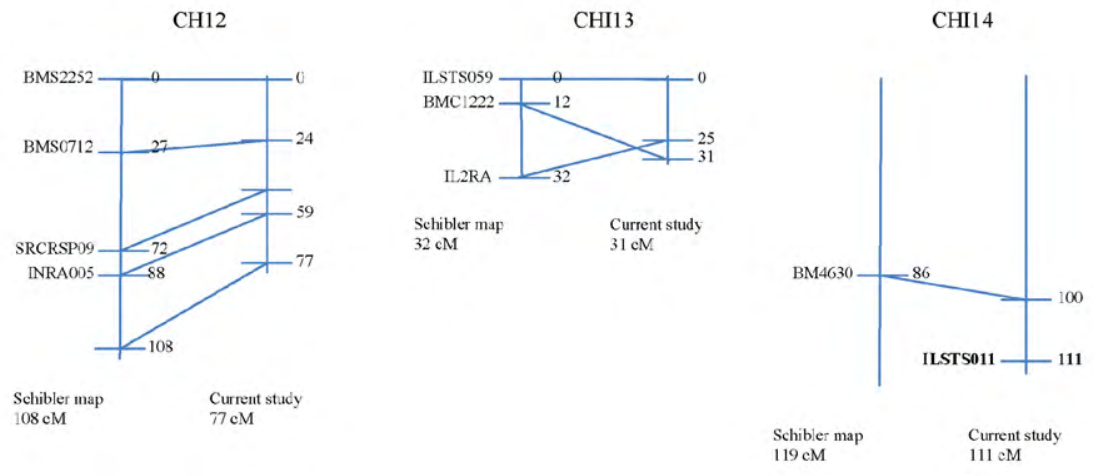

CHI16

CHI17
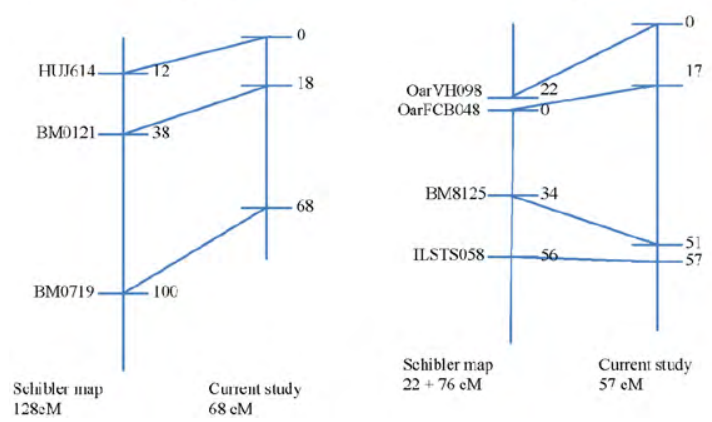

CHI18

CH19
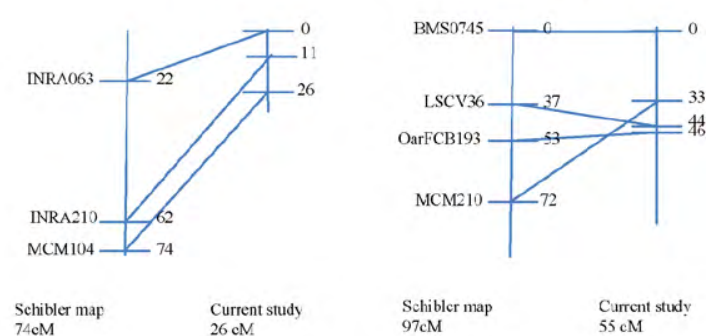

$\begin{array}{ll}\text { Schibler map } & \text { Current study } \\ 97 \mathrm{cM} & 55 \mathrm{cM}\end{array}$ $22+76 \mathrm{cM}$

$74 \mathrm{eM}$

Fig. 1. Alignment of the marker order of the current study with the most recent goat linkage map (Schibler et al., 1998). Marker names and positions are only given for microsatellites that have been mapped in this study. 
CHI20

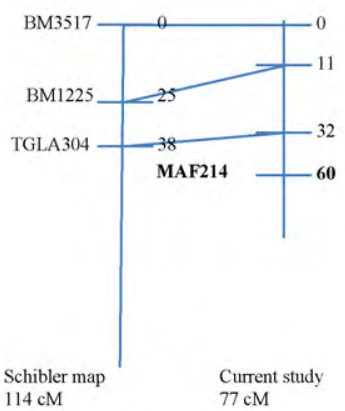

CHI27

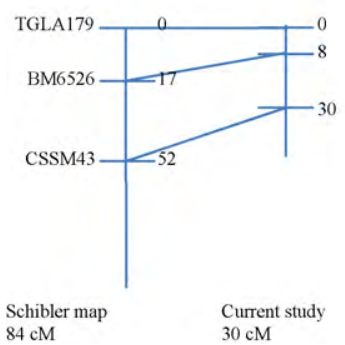

CHI23

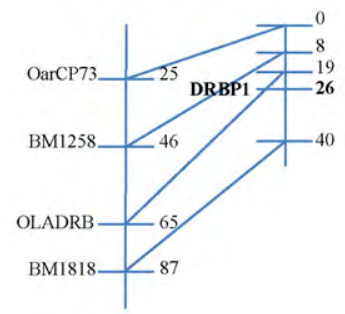

Schibler map $87 \mathrm{cM}$

Current study $40 \mathrm{cM}$
CHI24

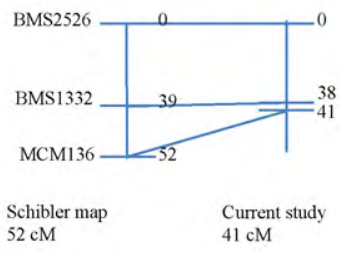

CHI25

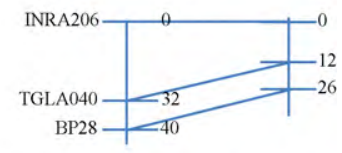

Schibler map

Current study

$40 \mathrm{cM}$

Fig. 1. (Continued)

Schibler et al. (1998). Some of these markers have either not previously been conclusively assigned to specific chromosomes (e.g. SRCRSP08, OarCP26, OarCP34 and DRBP1) or to specific orders (e.g. SRCRSP24, BMC1009, ILSTS087, ILSTS011 and MAF214). Inversions to the Schibler et al. (1998) map were found on CHI2, CHI4, CHI5, CHI11, CHI13 and CHI19, and matrices indicating the recombination fractions and LOD scores between the markers on these chromosomes are presented in Table 3. These re-assignments were then compared with the Vaiman et al. (1996) goat map and the ovine map, both (Maddox et al., 2001) and the updated SheepMap4.7 (http://www.ncbi.nlm.nih.gov/mapview/static/sheepsearch.htm

\section{Discussion}

The use of half-sib paternal families for mapping projects is popular because of the relative ease with which sufficient data can be generated. The disadvantage of not having maternal linkage information is a reduced efficiency of the mapping project (Crawford et al., 1994). Despite this limitation, it is still the most popular experimental design in livestock and half-sib population structures of a reasonable size can be generated. The previously published goat maps (Vaiman et al., 1996; Schibler et al., 1998) made use of this design, as did the current study. Although marker phase is difficult to infer in natural populations, it was shown through simulation studies by Slate (2008) that linkage maps constructed from natural populations are reasonable robust and accurate.

The marker order found in this study corresponded with that of the most recent goat map (Schibler et al.,
1998) for 15 of the chromosomes, although shorter map lengths are generally reported in this study. The marker order on chromosomes $\mathrm{CHI} 2, \mathrm{CHI} 4, \mathrm{CHI} 5, \mathrm{CHI} 11, \mathrm{CHI} 13$ and CHI19 however varied from those reported by Schibler et al. (1998). The relative marker distances between the studies also differed, which was expected as chromosome lengths is a property of the population under study (Slate, 2008) and incorrect mapping usually result in inflated maps. The average number of informative meiosis $(518 \pm 179)$ in our study was much higher than the $114 \pm 70$ reported by Schibler et al. (1998), resulting in a more accurate linkage map. Furthermore, both Vaiman et al. (1996) and Schibler mb)t al. (1998) reported results without taking Kosambi's correction into account, while the current study made use of Kosambi's mapping function. This function assumes a moderate amount of positive interference between adjacent regions (Weller, 2001) and generally results in shorter map lengths. Many published linkage maps use the function as the recombination data recorded over the past decades mostly corresponds to Kosambi's function (Huehn, 2010).

Despite the overall good agreement of the caprine and ovine maps, a large number of discrepancies have been reported between them (Maddox, 2005), including inter-chromosomal re-assignments. Many of these discrepancies are thought to be artefacts, due to the relatively low robustness, small number of markers and little error checking of the much older goat maps (Maddox, 2005). In the case of any inversions between the current study and the Schibler et al. (1998) map, further comparisons were made to the ovine map (SheepMap4.7: http:// www.ncbi.nlm.nih.gov/mapview/static/sheepsearch.html) and/or to the earlier goat map (Vaiman et al., 1996). The 
Table 3

Matrices indicating linkage groups per chromosome for chromosomes with discrepancies compared to Schibler et al. (1998). Recombination fraction above and LOD score below the diagonal.

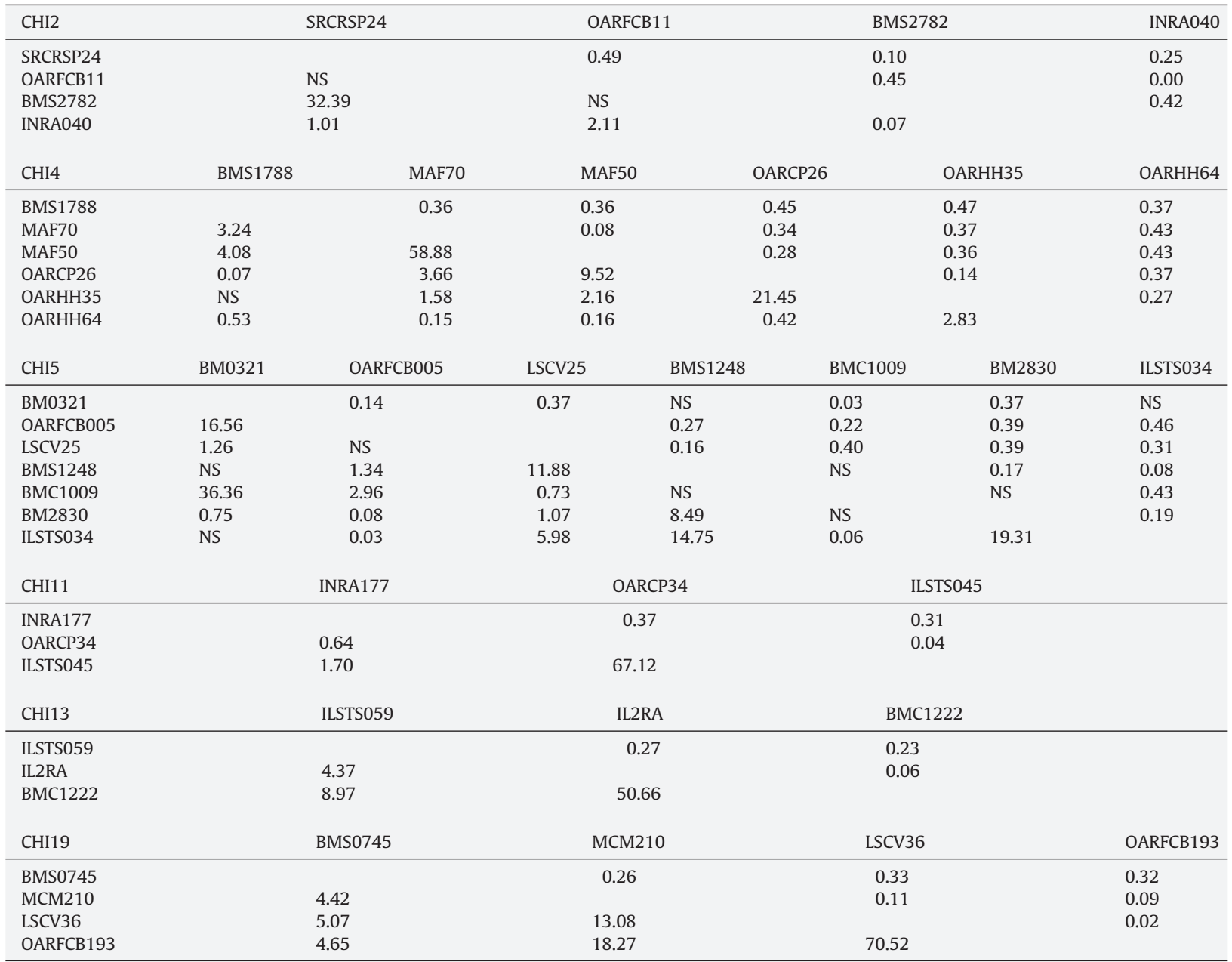

relative marker orders for the chromosomes with potential rearrangements are shown in Fig. 2. Vaiman et al. (1996) did not report map positions, but only intervals between markers, making it difficult to compare locations. Many of the chromosomes are also represented in more than one fragment. For this reason, it was not included in the graphical representation of Fig. 2. Rearrangements are reported in Table 3 , with their respective pair-wise recombination fractions and LOD scores. Not all markers within the specific linkage groups for $\mathrm{CHI} 2, \mathrm{CHI} 4$ and $\mathrm{CHI} 5$ showed linkage to each other. In these cases both markers could however be linked to a common third marker.

The new position of OarHH64 on CHI4 corresponds to its position on OAR4. Both Vaiman et al. (1996) and Schibler et al. (1998) divided CHI4 into two linkage groups, making it difficult to compare positions. The inversion of markers BM0321 and OarFCB005 on CHI5 is however consistent with the order reported by Vaiman et al. (1996). BM0321 has not yet been mapped to any ovine chromosome, thus map positions could not be compared. The relative positions of OarFCB005 and BMC1009 (adjacent to BM0321) do however correspond to those reported on
SheepMap4.7. OarCP34 has not previously been ordered on CHI11, while the inversion of ILSTS045 and its close proximity to OarCP34 corresponds to its relative position on OAR3. Vaiman et al. (1996) only reports the position of INRA 177 on bovine BTA11, while OarCP34 was not mapped at all. Markers LSCV36 and MCM210 on CHI19 were inverted in the current study. This order is in agreement with OAR11 on SheepMap4.7. These rearrangements in chromosomal order seem to be the correct order of the markers, and the previously reported orders which showed inversions compared to the ovine map were most likely either population specific or due to problems with map assembly. The rearrangements are also supported by the reduced genetic length of the new map.

Linkage map CHI2 was mapped in two linkage groups by Vaiman et al. (1996), making it difficult to compare map positions. The two markers INRA040 and OarFCB11 on CHI2 are spaced far from each other on both the goat map of Schibler et al. (1998) and the SheepMap4.7. Their inversion and close proximity reported in this study seems to be population specific to the South African Angora goat. The inversion of markers BMC1222 and IL2RA on CHI13 corre- 


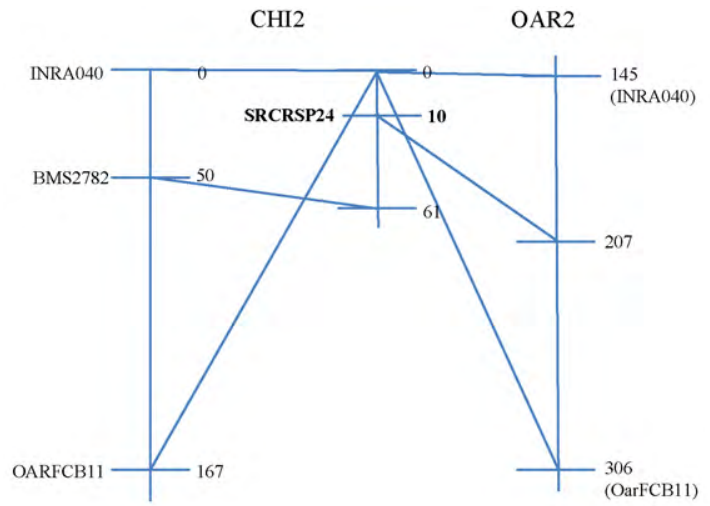

Schibler map

Current study

CHI5

OAR3

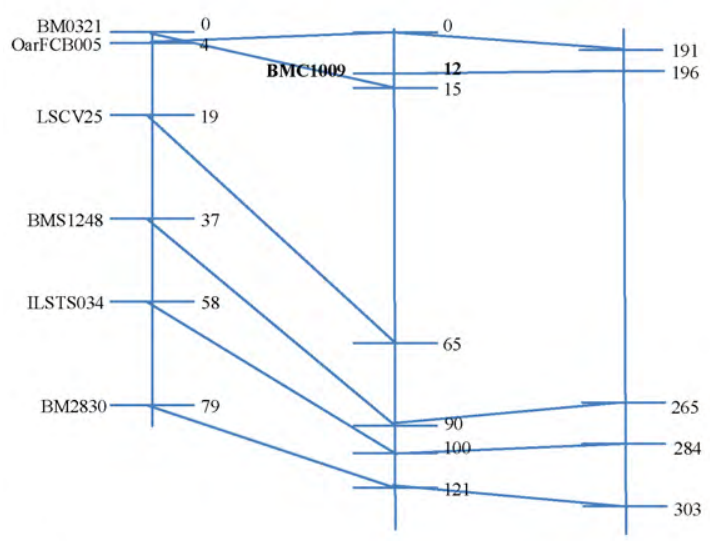

Schibler map

Current study

SheepMap4.7

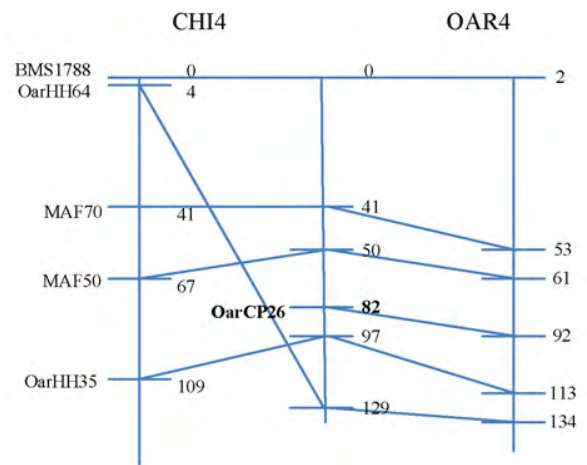

Schibler map

Current study

SheepMap4.7
$\mathrm{CHI} 13$

OAR13

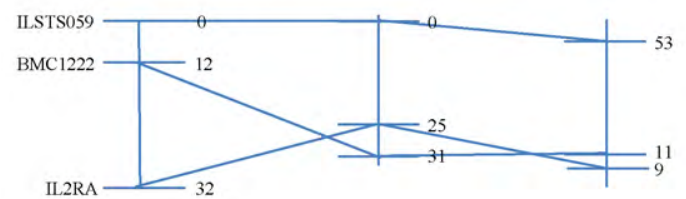

Schibler map

SheepMap4,7

SheepMap4.7

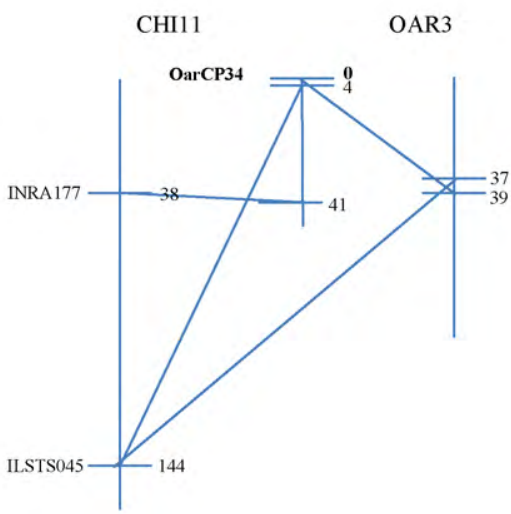

Schibler map
Current study SheepMap4.7
CHI19

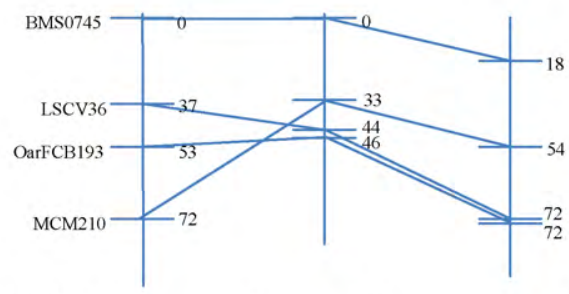

Schibler map

Current study

SheepMap4.7

Fig. 2. Alignment of marker orders on $\mathrm{CHI} 2,4,5,11,13$ and 19 with orders compared between the current study, the goat map of Schibler et al. (1998) and SheepMap4.7 (http://www.ncbi.nlm.nih.gov/mapview/static/sheepsearch.html).

sponds with position reported by Vaiman et al. (1996), but is in disagreement with the order on OAR13.

The new positions of anonymous markers on the goat map, as well as the correction of previously reported inversions (compared to the ovine map) will contribute to the improvement and accuracy of the goat map. The improved caprine linkage maps will assist with comparative mapping of economically significant loci, which could result in the application of marker assisted selection.

\section{Conclusion}

The accuracy and coverage of the goat map will be increased significantly once SNPs are available for genome mapping in goats. Until then, microsatellite markers have made an essential contribution to the development of caprine genome maps. No effort has been made to date to verify previously reported inter-chromosomal rearrangements. The correction of these inversions (compared to 
the ovine map) will contribute to the development of a robust caprine linkage map. The use of a large population which resulted in a significant improvement in the number of informative meiosis and shorter mapping distances has lead to the advancement of the caprine linkage map, and should in future be the basis of an advanced linkage map. A more complete and accurate map should lead to the opportunity of mapping genetic variation that is responsible for the phenotypic differences in economically important traits.

\section{References}

Allan, M.F., Smith, T.P.L., 2008. Present and future applications of DNA technologies to improve beef production. Meat Sci. 80, 79-85.

Baumung, R., Simianer, H., Hoffmann, I., 2004. Genetic diversity studies in farm animals-a survey. J. Anim. Breed. Genet. 121, 361-373.

Cosenza, G., Pauciullo, A., Gallo, D., Colimolro, L., D’Avino, A., Mancusi, A., Rammuno, L., 2008. genotyping at the CSN1S1 locus by PCR-RFLP and AS-PCR in a Neapolitan goat population. Small Rumin. Res. 74, 84-90.

Crawford, A.M., Montgomery, G.W., Pierson, C.A., Brown, T., Dodds, K.G., Sunden, S.L.F., Henry, H.M., Ede, A.J., Swarbick, P.A., Berryman, T., Penty, J.M., Hill, D.F., 1994. Sheep linkage mapping: nineteen linkage groups derived from the analysis of paternal half-sib families. Genetics $137,573-579$

Dubeuf, J.P., Boyazoglu, J., 2009. An international panorama of goat selection and breeds. Livest. Sci. 120, 225-231.

Faraut, T., De Givry, S., Hitte, C., Lahbib-Mansais, Y., Morisso, M., Milan, D., Schiex, T., Servin, B., Vignal, A., Galibert, F., Yerle, M., 2009. Contribution of radiation hybrids to genome mapping in domestic animals. Cytogenet. Genome Res. 126, 21-33.

Green, P., Falls, K., Crooks, S., 1989. Documentation for CRI-MAP, Version 2.4. Washington University, St. Louis.

Gupta, N., Pandey, A., Malik, G., Gupta, S.C., 2009. Single nucleotide polymorphism (SNP) in growth hormone gene of Jakhrana, a prominent milk goat breed in India. Small Rumin. Res. 81, 35-41.

Huehn, M., 2010. Random variability of map distances based on Kosambi's and Haldane's mapping functions. J. Appl. Genet. 51 (1), 27-31.

Loots, F., 2007. Seisoenoorsig. The Angora goat and Mohair Journal, PO Box 50 , Jansenville 6265, South Africa.

Maddox, J.F., 2005. A presentation of the differences between the sheep and goat genetic maps. Genet. Sel. Evol. 37 (Suppl. 1), S1-S10.
Maddox, J.F., Cockett, N.E., 2007. An update on sheep and goat linkage maps and other genomic resources. Small Rumin. Res. 70 (1), 4-20.

Maddox, J.F., Davies, K.P., Crawford, A.M., Hulme, D.J., Vaiman, D., Cribiu, E.P., Freking, B.A., Beh, K.J., Cockett, N.E., Kang, N., Riffkin, C.D., Drinkwater, R., Moore, S.S., Dodds, K.G., Lumsden, J.M., Van Stijn, T.C., Phua, S.H., Adelson, D.L., Burkin, H.R., Broom, J.E., Buitkamp, J., Cambridge, L., Cushwa, W.T., Gerard, E., Galloway, S.M., Harrison, B., Hawken, R.J., Hiendleder, S., Henry, H.M., Medrano, J.F., Paterson, K.A., Schibler, L., Stone, R.T., Van Hest, B., 2001. An enhanced linkage map of the sheep genome comprising more than 1000 loci. Genome Res. $11,1275-1289$.

Marshall, T.C., Slate, J., Kruuk, L.E.B., Pemberton, J.M., 1998. Statistical confidence for likelihood-based paternity inference in natural populations. Mol. Ecol. 7 (5), 639-655.

Moioli, B., D’Andrea, M., Pilla, F., 2007. Candidate genes affecting sheep and goat milk quality. Small Rumin. Res. 68, 179-192.

Notter, D.R., Baker, R.L., Cockett, N.E., 2007. The outlook for quantitative and molecular genetic applications in improving sheep and goats. Small Rumin. Res. 70, 1-3.

Prasad, A., Schiex, T., McKay, S., Murdoch, B., Wang, Z., Womack, J.E., Stothard, P., Moore, S.S., 2007. High resolution radiation hybrid maps of bovine chromosomes 19 and 29: comparison with the bovine genome sequence assembly. BMC Genomics 8, 310-319.

Schibler, L., Vaiman, D., Oustry, A., Giraud-Delville, C., Cribou, E.P., 1998. Comparative gene mapping: a fine-scale survey of chromosome rearrangements between ruminants and humans. Genome Res. 8, 901-915.

Slate, J., 2008. Robustness of linkage maps in natural populations: a simulation study. Proc. R. Soc. B 275, 695-702.

Sonstegard, T.S., Van Tassell, C.P., Ashwell, M.S., 2001. Dairy cattle genomics: tools to accelerate genetic improvement. J. Anim. Sci. 79 (E Suppl.), E307-E315.

Toro, M.A., Fernandez, J., Caballero, A., 2009. Molecular characterization of breeds and its use in conservation. Livest. Sci. 120, 174-195.

Vaiman, D., Schibler, L., Bourgeois, F., Oustry, A., Amigues, Y., Cribiu, E.P., 1996. A genetic linkage map of the male goat genome. Genetics 144 , 279-305.

Vaiman, D., Pailhoux, E., Schibler, L., Oustry, A., Chaffaux, S., Cotinot, C., Fellous, M., Cribou, E.P., 1997. Genetic mapping of the polled/intersex locus (PIS) in goats. Theriogenology 47, 103-109.

Vignal, A., Milan, D., SanCristobal, M., Eggen, A., 2002. A review on SNP and other types of molecular markers and their use in animal genetics. Genet. Sel. Evol. 34, 275-305.

Weller, J.I., 2001. Quantative Trait Loci Analysis in Animals. CABI Publishing, Oxon, United Kingdom, pp. 10-11. 